BMJ Open

Sport \&

Exercise

Medicine

\title{
Haemoglobin, iron status and lung function of adolescents participating in organised sports in the Finnish Health Promoting Sports Club Study
}

Kerttu Toivo (D), ${ }^{1,2}$ Pekka Kannus, ${ }^{1}$ Sami Kokko, ${ }^{3}$ Lauri Alanko, ${ }^{4,5}$ Olli J Heinonen, ${ }^{6}$ Raija Korpelainen, ${ }^{7,8,9}$ Kai Savonen, ${ }^{10,11}$ Harri Selänne, ${ }^{12}$ Tommi Vasankari, ${ }^{2}$ Lasse Kannas, ${ }^{3}$ Urho M Kujala, ${ }^{3}$ Jari Villberg, ${ }^{3}$ Onni Niemelä, ${ }^{13}$ Jari Parkkari, ${ }^{1,2,14}$

To cite: Toivo $\mathrm{K}$, Kannus $\mathrm{P}$, Kokko S, et al. Haemoglobin, iron status and lung function of adolescents participating in organised sports in the Finnish Health Promoting Sports Club Study. BMJ Open Sport \& Exercise Medicine 2020;0: e000804. doi:10.1136/ bmjsem-2020-000804

- Supplemental material is published online only. To view please visit the journal online (http://dx.doi.org/10.1136/ bmjsem-2020-000804).

Accepted 19 August 2020
Check for updates

(c) Author(s) (or their employer(s)) 2020. Re-use permitted under CC BY-NC. No commercial re-use. See rights and permissions. Published by BMJ.

For numbered affiliations see end of article.

Correspondence to Kerttu Toivo; kerttu. toivo@fimnet.fi

\section{ABSTRACT}

Objectives To compare laboratory test results and lung function of adolescent organised sports participants (SP) with non-participants (NP).

Methods In this cross-sectional study, laboratory tests (haemoglobin, iron status), and flow-volume spirometry were performed on SP youths (199 boys, 203 girls) and their NP peers (62 boys, 114 girls) aged 14-17. Results Haemoglobin concentration $<120 / 130 \mathrm{~g} / \mathrm{L}$ was found in $5.8 \%$ of SP and $5.1 \%$ NP (OR 1.20, 95\% Cl 0.54 to 2.68). Ferritin concentration below $15 \mu \mathrm{g} / \mathrm{L}$ was found in $22.7 \%$ of both SP and NP girls. Among boys ferritin $<30 \mu \mathrm{g} / \mathrm{L}$ was found in $26.5 \%$ of SP and $30.2 \%$ of NP (OR $0.76,95 \% \mathrm{Cl} 0.40$ to 1.47). Among SP iron supplement use was reported by $3.5 \%$ of girls and $1.5 \%$ of boys. In flowvolume spirometry with bronchodilation test, $7.0 \%$ of SP and $6.4 \%$ of NP had asthma-like findings (OR 1.17, $95 \% \mathrm{Cl}$ 0.54 to 2.54); those using asthma medication, that is, $9.8 \%$ of SP and $5.2 \%$ of NP were excluded from the analysis.

Conclusions Screening for iron deficiency is recommended for symptomatic persons and persons engaging in sports. Lung function testing is recommended for symptomatic persons and persons participating in sports in which asthma is more prevalent.

\section{INTRODUCTION}

Prevention of injury and illness is the cornerstone of sports medicine. ${ }^{1}$ Haemoglobin concentration is positively associated with maximal oxygen uptake which is an important determinant of an athlete's performance potential, especially in endurance sports. Depleted iron stores are known to reduce haemoglobin mass. ${ }^{2}$ Studies have revealed low iron storage levels in up to $50 \%$ of adolescent females, and iron-deficiency anaemia in 5-10\%, with anaemia being no more common among athletes than non-athletes. ${ }^{3} 4$ The effect of iron supplementation on exercise performance in athletes with iron deficiency varies between studies. ${ }^{5}$

\section{What are the new findings}

Twenty-three per cent of 14-17-year-old girls in both groups had ferritin levels below 15 suggesting iron store depletion.

- Among boys, $27 \%$ of sports participants and $30 \%$ of non-participants had ferritin concentration below 30 .

- Iron deficiency was undertreated. Supplemental iron use was reported by $3.5 \%$ of girls and $1.5 \%$ of boys participating in sports and by none of the nonparticipants.

- Bronchial hyper-responsiveness may be an undertreated condition among adolescents. Among those who did not use asthma medication, a bronchodilator response consistent with asthma was found in $7 \%$ of sports participants and in $6.4 \%$ of non-participants.

Asthma is a chronic respiratory disorder often coexisting with atopy, allergies and chronic rhinosinusitis. ${ }^{67}$ It is an inflammatory disease, causing difficulty in breathing and leading to increased energy expenditure. ${ }^{8}$ Twenty per cent of young Finnish adults report a history of allergies and/or atopy and $5 \%$ report physician-diagnosed asthma. ${ }^{9}$ Adults typically suffer 2-3 upper respiratory infections yearly, ${ }^{10}$ and athletes more often than others. ${ }^{11}$ The focus of this descriptive study is on clinical laboratory findings among adolescent sports participant (SP) with an emphasis on anaemia, iron deficiency and asthma detection.

\section{METHODS}

This cross-sectional study was a part of the Finnish Health Promoting Sports Club study conducted by the University of Jyväskylä together with six national Centres of 
Excellence in Sports and Exercise Medicine located in different regions of Finland, as well as the UKKinstitute. ${ }^{12}$ A total of 240 youth sports clubs active in the country's 10 most popular sports were targeted, with the goal to produce a representative sample of the most popular individual and team youth sports. Both summer and winter sports were included. ${ }^{12}$ The data were collected over 14 months. Non-participant (NP) were recruited from schools (9th grade). The 578 adolescents were aged 14-17 (402 SP, 50\% females and 179 NP, $64 \%$ females). All completed a medical history questionnaire at home with their parents. ${ }^{12}$ The questionnaire was reviewed at the beginning of a health examination by a sports and exercise medicine specialist. $^{12}$

Venous blood samples were taken after a $\geq 10$-hour fast and haemoglobin was determined with a standard automatic haematology analyser. Serum was separated by standard procedures and stored at $-75^{\circ} \mathrm{C}$ for future analysis. Anaemia was defined as $\mathrm{Hb}<120 \mathrm{~g} / \mathrm{L}$ for all females and males under 15 years, the threshold for males $\geq 15$ years was $<130 \mathrm{~g} / \mathrm{L}$ as recommended by the WHO. Blood chemistry, serum ferritin and transferrin receptor analyses were carried out on a Cobas 8000 modular analyser (Roche Diagnostics) in an SFS-EN ISO 15 189:2013 accredited laboratory. Subjects with C-reactiveprotein levels indicating inflammation, that is, $>5 \mathrm{mg} / \mathrm{L}$ were excluded from the ferritin analyses. Additionally, subjects taking iron supplements who had normal ferritin levels $(>30 \mu \mathrm{g} / \mathrm{L})$ were excluded from ferritin and transferrin receptor analyses. Ferritin concentrations were obtained from 561 subjects, and transferrin receptor concentrations from 567 subjects. Two ferritin concentrations were used to indicate iron deficiency $<15 \mu \mathrm{g} / \mathrm{L}$ and $<30 \mu \mathrm{g} / \mathrm{L} .{ }^{13}{ }^{14}$ A lower ferritin threshold to indicate iron deficiency is commonly used for females. The laboratory-specific reference range for serum transferrin receptor was 2.2-5.0 mg/L for males and 1.9-4.4 mg/L for females.

Height and weight were measured and recorded. Flow-volume spirometry was measured according to American Thoracic Society/European Respiratory Society guidelines ${ }^{15}$ using a Medikro Pro 909 Spirometer (Kuopio, Finland). Finnish reference values for children were used. ${ }^{16}$ Salbutamol $0.4 \mu \mathrm{g}$ was used for the bronchodilation test. Subjects reporting asthma medication use $(n=48)$ were excluded from the analysis as well as those, whose results were deemed unreliable due to technical shortcomings $(n=63)$. Additionally, 21 subjects had poor quality results after the bronchodilator administration, and these were also excluded. An asthma diagnosis was not an exclusion criterion if the person was not using asthma medication regularly. The number of spirometry tests included in the analysis was 515. The criteria for baseline obstruction were FEV\% z-score <-1.65 and for new asthma diagnosis FEV1 (forced expiratory volume in 1 second) or FVC (forced vital capacity) $+12 \%$ in the bronchodilation test. ${ }^{17}$

\section{Statistical methods}

Dichotomous variables are shown as numbers and percentages of participants and NP, separately for boys and girls and in total. Differences between the groups were assessed using generalised linear-mixed models. A two-tier data structure was constructed, the subject being level 1, and the Centre of Excellence in Sports and Exercise Medicine being level 2. For continuous variables, either normal distribution or gamma distribution was used depending on the normality of the outcome variable. For dichotomous variables, binomial distribution was used to obtain ORs. Coefficients and ORs are reported with 95\% CIs. IBM SPSS (v.26.0) was used to carry out all analyses.

\section{RESULTS}

\section{Basic characteristics}

SP were slightly taller than NP $171 \mathrm{~cm}$ vs $169 \mathrm{~cm}$ (coefficient $0.01,95 \%$ CI 0.05 to 0.02 ) (table 1 ). Online supple mental table 1 shows the sports participated in by each sex.

\section{Haemoglobin and iron status}

Haemoglobin $<120 / 130$ was present in $5.8 \%$ of SP and in $5.1 \%$ of NP (OR $1.20,95 \%$ CI 0.54 to 2.68). Ferritin concentrations $<15 \mu \mathrm{g} / \mathrm{L}$ was found in $22.7 \%$ of both SP and NP girls. Ferritin $<30 \mu \mathrm{g} / \mathrm{L}$ was found in $26.5 \%$ of SP boys and $30.2 \%$ for NP boys (OR $0.76,95 \%$ CI 0.40 to 1.47). The use of an iron supplement was rare in all groups (table 2).

\section{Allergies and asthma}

Recurrent skin rash was less common in SP than NP ( $15.1 \%$ vs $23.6 \%$, OR $0.63,95 \%$ CI 0.40 to 0.99$)$. SP tended to use asthma medication more frequently NP $(9.8 \%$ vs $5.2 \%)$, the difference was not statistically significant (OR 1.74, 95\% CI 0.86 to 3.53). In baseline spirometry, a low FEV\% suggestive of pulmonary obstruction was found in $16.5 \%$ of SP and $15.3 \%$ of NP. A significant bronchodilator response was observed in $7 \%$ of SP and $6.4 \%$ of NP (OR 1.17, 95\% CI 0.54 to 2.54 ), those using asthma medication were excluded from the analysis. Girls who reported dyspnoea during exercise were more likely to have a significant bronchodilator response in flow-volume spirometry (OR 3.17, 95\% CI 1.12 to 9.02 ). When looking at boys and girls together this finding was not statistically significant (OR 2.05, $95 \%$ CI 0.80 to 5.27 ). None of the 13 boys who reported dyspnoea during exercise had a significant bronchodilator response (table 3 ).

\section{DISCUSSION}

Iron deficiency was a common finding in both groups. However, iron supplement use was reported by only $3.5 \%$ of SP girls and $1.5 \%$ of SP boys. NP reported no 


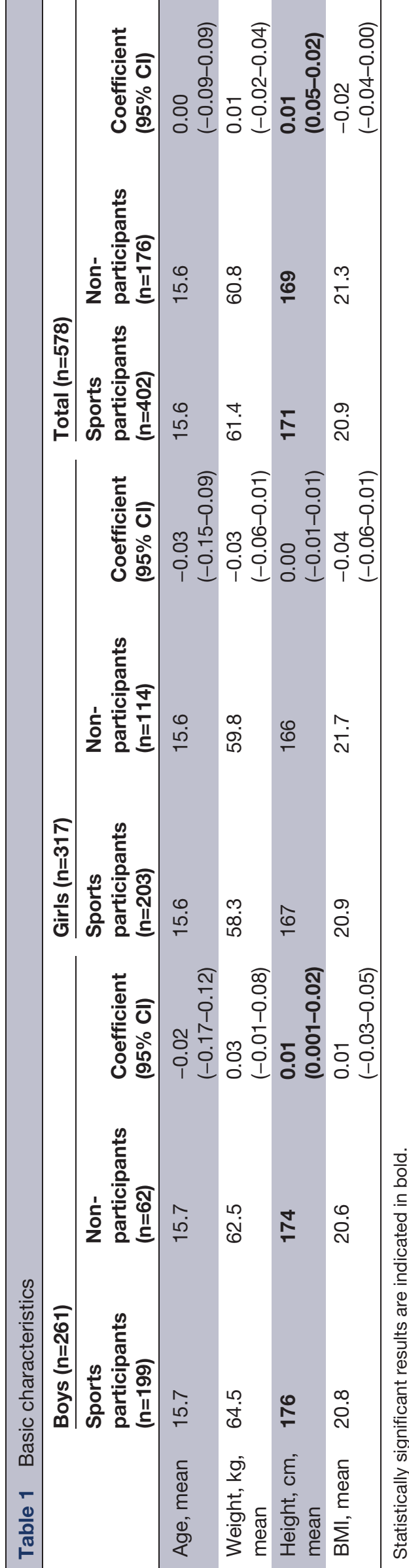

use of iron supplements. The serum ferritin concentrations used to define iron deficiency vary between studies, frequently falling within the $15-30 \mu \mathrm{g} / \mathrm{L}$ range. ${ }^{4} 131418$ Iron deficiency in athletes is thought to be caused by reduced dietary iron and increased requirements associated with exercise. ${ }^{19}$ Iron deficiency is more common in females than males across studies as well as in our study ${ }^{18} 20$ and it is known that the onset and duration of menstruation affect iron status. ${ }^{21}$ The roles of several minerals and trace elements in improving athletic performance have been studied, with iron and magnesium having the strongest quality evidence. ${ }^{5}$

The use of allergy medication has previously been found to be more common in athletes than nonathletes, but no difference between the groups was found in this study. ${ }^{22}$ It was found that only half of the athletes who reported allergic rhinitis reported using allergy medication within the past year. ${ }^{22}$ Among those who did not use asthma medication, a bronchodilator response consistent with asthma was found in $7 \%$ of SP and $6.4 \%$ of NP. We found no statistically significant difference in use of asthma medication between SP and NP, although other studies show that asthma is more prevalent among endurance athletes, especially those exposed to cold and dry air, and in swimmers. ${ }^{23}$

The strengths of this study were that both summer and winter sports and individual and team sports were equally represented. ${ }^{24}$ The prevalence of the various health conditions and problems was similar to those found in other studies indicating that the study sample represented typical adolescents. Our study also contained certain limitations. First, the questionnaire in the study was based on self-reported data, which is a potential issue for recall bias. However, sports and exercise medicine physicians reviewed all the questions with the study subjects, which should improve the accuracy of the collected data. Second, since the drop-out rate from sports participation is high in adolescence it is likely that a proportion of the NP's had just recently withdrawn from sports club activities thus blurring the difference between SP and NP. It should also be conceded that regarding SP as a single homogenous group ignores the difference in the frequency and intensity of PA between individuals and between different sports.

Health is an important determinant of sports performance and to maximise the amount of healthy training days, medical conditions should be identified and managed adequately. Iron deficiency is common and undertreated among adolescents and screening is recommended for symptomatic persons and persons engaging in sports. Lung function testing is recommended for persons with a family history of bronchial hyper-responsiveness, asthma-like symptoms and persons participating in sports in which asthma is more prevalent. 


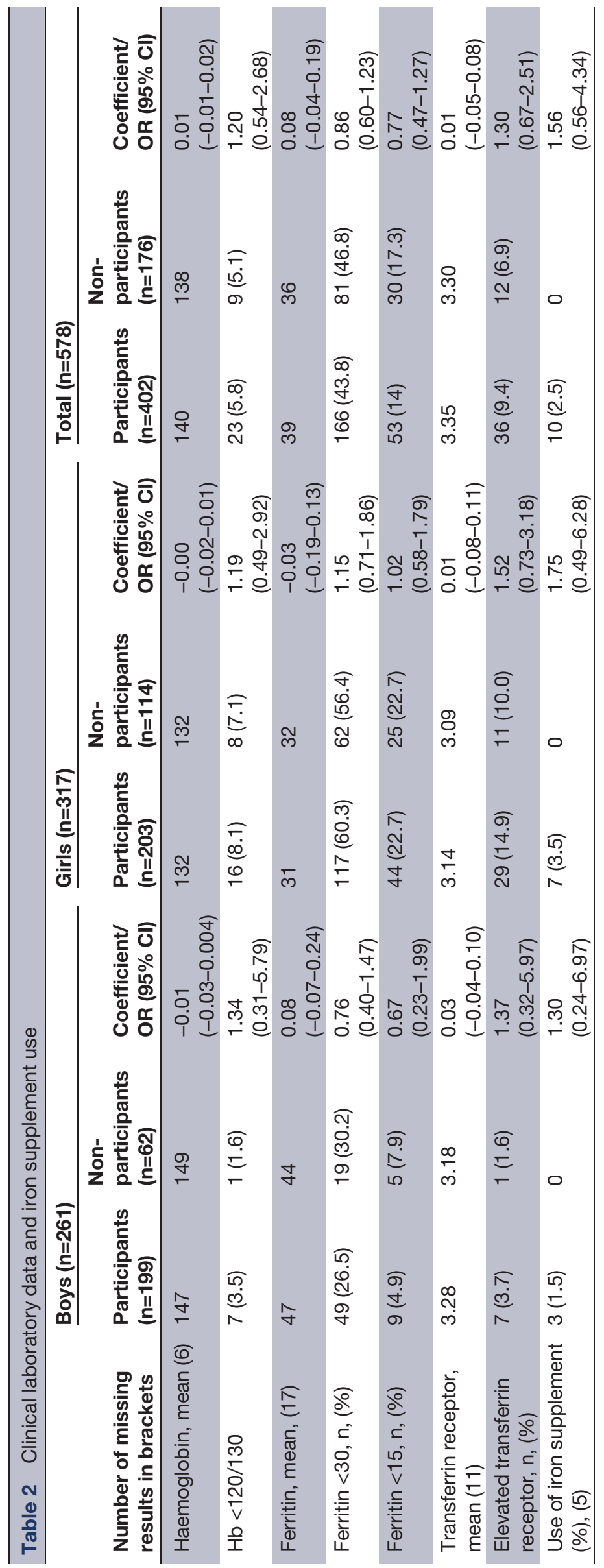




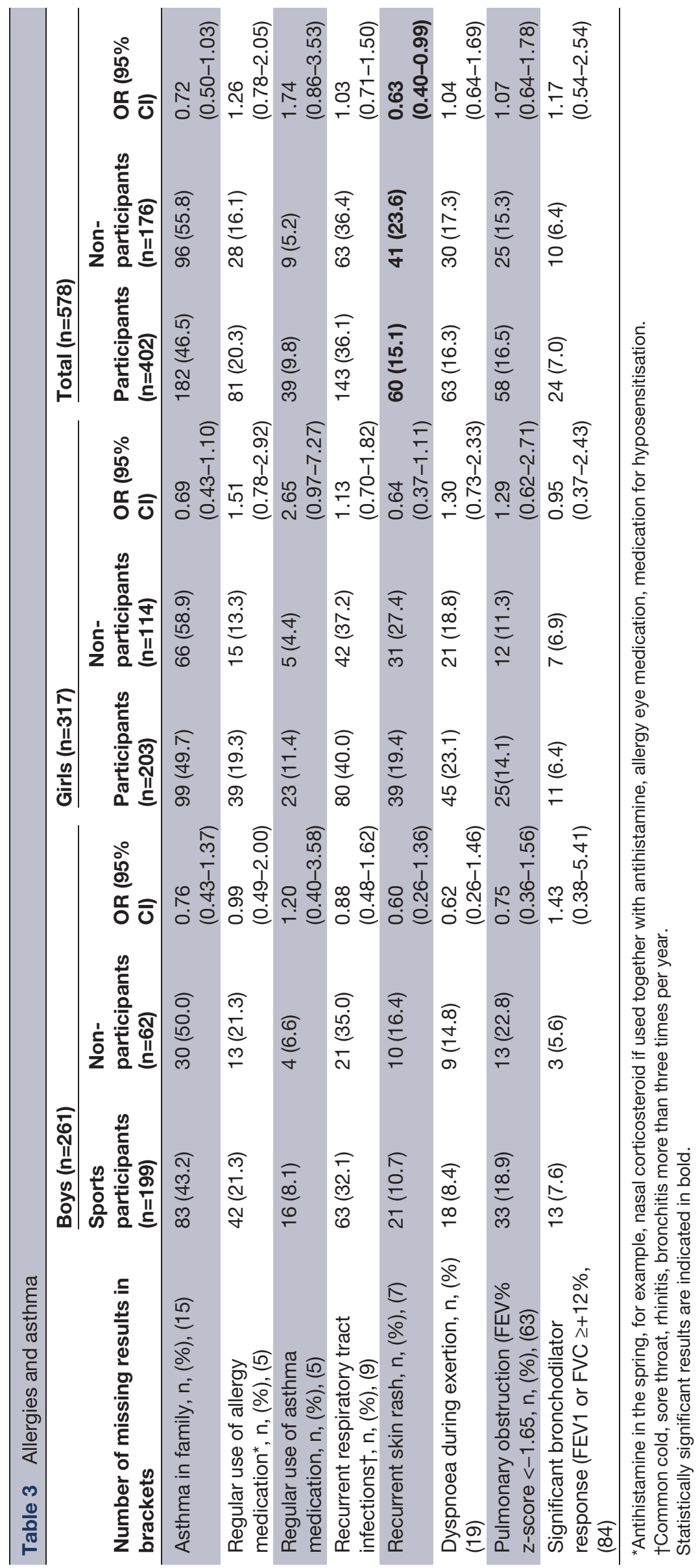


Author affiliations

${ }^{1}$ Tampere Research Center of Sports Medicine, Ukk Institute, Tampere, Finland

${ }^{2}$ Ukk Institute for Health Promotion Research, Tampere, Finland

${ }^{3}$ Faculty of Sport and Health Sciences, University of Jyvaskyla, Jyvaskyla, Finland

${ }^{4}$ Clinic for Sports and Exercise Medicine, Helsingin Yliopisto, Helsinki, Finland

${ }^{5}$ Department of Sports and Exercise Medicine, Central Finland Central Hospital,

Jyvaskyla, Finland

${ }^{6}$ Paavo Nurmi Centre \& Unit for Health and Physical Activity, University of Turku,

Turku, Finland

${ }^{7}$ Department of Sports and Exercise Clinic, Oulu Deaconess Foundation, Oulu,

Finland

${ }^{8}$ Center for Life Course Health Research, University of Oulu, Oulu, Finland

${ }^{9}$ Medical Research Center, University of Oulu and University Hospital of Oulu, Oulu,

Finland

${ }^{10}$ Kuopio Research Institute of Exercise Medicine, Kuopio, Finland

${ }^{11}$ Department of Clinical Physiology and Nuclear Medicine, Kuopio University

Hospital, Kuopio, Finland

${ }^{12}$ Department of Psychology, University of Jyväskylä, Jyvaskyla, Finland

${ }^{13}$ Department of Laboratory Medicine and Medical Research Unit, Seinajoki Central

Hospital and University of Tampere, Seinajoki, Finland

${ }^{14}$ The Research Services, Tampere University Hospital, Tampere, Finland

Acknowledgements The authors wish to thank all the participating sports clubs, their officials and coaches. The authors also thank the participating schools for their responses to the questionnaires. The authors would like to express their gratitude to all the young people who took part in this study, especially those who took part in the preparticipation screening. Without their involvement, this study would not have been possible.

Contributors All the authors contributed to the substance and design of the study. SK and JP compiled and collated the sections of the study. KT carried out the literature search. SK and JV collected and arranged the preliminary data. ON contributed to the laboratory analyses. KT and JV conducted the data analyses and all the authors participated in the interpretation of data. KT, PK and JP wrote the first draft of the paper and all authors provided substantive feedback on the paper and contributed to the final manuscript. All authors have approved the submitted version of the manuscript. JP acts as the guarantor.

Funding This study was financially supported by the Finnish Ministry of Education and Culture (major, grant number: 6/091/2011) and Ministry of Social Affairs and Health (minor, grant number: 152/THL/TE/2012).

Competing interests None declared.

Patient consent for publication The adolescents and their guardians provided written consent to participate in the study, and the adolescents were told that they could retract their consent at a later date.

Ethics approval The study conforms to the declaration of Helsinki. A positive statement from the Ethics Committee of healthcare District of Central Finland was received (record number 23U/2012). Before the start of this study, we requested permission from all the sports clubs to take part. This permission was granted freely.

Provenance and peer review Not commissioned; externally peer reviewed.

Data availability statement The data may not be shared because permission was not requested from the participants or their parents.

Supplemental material This content has been supplied by the author(s). It has not been vetted by BMJ Publishing Group Limited (BMJ) and may not have been peer-reviewed. Any opinions or recommendations discussed are solely those of the author(s) and are not endorsed by BMJ. BMJ disclaims all liability and responsibility arising from any reliance placed on the content. Where the content includes any translated material, BMJ does not warrant the accuracy and reliability of the translations (including but not limited to local regulations, clinical guidelines, terminology, drug names and drug dosages), and is not responsible for any error and/or omissions arising from translation and adaptation or otherwise.

Open access This is an open access article distributed in accordance with the Creative Commons Attribution Non Commercial (CC BY-NC 4.0) license, which permits others to distribute, remix, adapt, build upon this work non-commercially, and license their derivative works on different terms, provided the original work is properly cited, appropriate credit is given, any changes made indicated, and the use is non-commercial. See: http://creativecommons.org/licenses/by-nc/4.0/.
ORCID iD

Kerttu Toivo http://orcid.org/0000-0002-4573-1937

\section{REFERENCES}

1 Engebretsen L, Steffen K. Protection of the elite athlete is the responsibility of all of us in sports medicine. Br J Sports Med 2015;49:1089-90.

2 Saunders PU, Garvican-Lewis LA, Schmidt WF, et al. Relationship between changes in haemoglobin mass and maximal oxygen uptake after hypoxic exposure. Br J Sports Med 2013;47:26-30.

3 Sandstrom G, Borjesson M, Rodjer S. Iron deficiency in adolescent female athletes - is iron status affected by regular sporting activity? Clin J Sport Med 2012;22:495-500.

4 Hallberg L, Hultén L, Lindstedt G, et al. Prevalence of iron deficiency in Swedish adolescents. Pediatr Res 1993;34:680-7.

5 Heffernan SM, Horner K, De Vito G, et al. The role of mineral and trace element supplementation in exercise and athletic performance: a systematic review. Nutrients 2019;11:696.

6 Toskala E, Kennedy DW. Asthma risk factors. Int Forum Allergy Rhinol 2015;5:S11-16.

7 Carlsen $\mathrm{KH}$, Anderson SD, Bjermer L, et al. Exercise-induced asthma respiratory and allergic disorders in elite athletes: epidemiology, mechanisms and diagnosis: part I of the report from the joint task force of the European Respiratory Society (ERS) and the European Academy of Allergy and Clinical Immunology (EAACI) in cooperation with GA2LEN. Allergy 2008;63:387-403.

8 Zeitlin SR, Bond S, Wootton S, et al. Increased resting energy expenditure in childhood asthma: does this contribute towards growth failure? Arch Dis Child 1992;67:1366-9.

9 Kilpeläinen M, Terho EO, Helenius $\mathrm{H}$, et al. Farm environment in childhood prevents the development of allergies. Clin Exp Allergy 2000;30:201-8

10 Heikkinen T, Jarvinen A. The common cold. Lancet 2003;361:51-9.

11 Valtonen $\mathrm{M}$, Waris $\mathrm{M}$, Vuorinen $\mathrm{T}$, et al. Common cold in team Finland during 2018 Winter Olympic Games (PyeongChang): epidemiology, diagnosis including molecular point-of-care testing (POCT) and treatment. Br J Sports Med 2019;53:1093-8.

12 Kokko S, Selänne H, Alanko L, et al. Health promotion activities of sports clubs and coaches, and health and health behaviours in youth participating in sports clubs: the health promoting sports club study. BMJ Open Sport Exerc Med 2015;1:e000034.

13 WHO. Iron deficiency anaemia: assessment, prevention and contro a guide for programme managers. 2001. Available https://www. who.int/nutrition/publications/en/ida_assessment_prevention_con trol.pdf

14 Hallberg L, Bengtsson C, Lapidus L, et al. Screening for iron deficiency: an analysis based on bone-marrow examinations and serum ferritin determinations in a population sample of women. $\mathrm{Br} \mathrm{J}$ Haematol 1993:85:787-98.

15 Miller MR, Hankinson J, Brusasco V, et al. Standardisation of spirometry. Eur Respir J 2005;26:319-38.

16 Koillinen $\mathrm{H}$, Wanne $\mathrm{O}$, Niemi $\mathrm{V}$, et al. Terveiden suomalaisten lasten spirometrian ja uloshengityksen huippu- virtauksen viitearvot. Spirometry and peak expiratory flow reference values in healthy Finnish children. Suomen Lääkärilehti 1998;395-402.

17 Pellegrino R, Viegi G, Brusasco V, et al. Interpretative strategies for lung function tests. Eur Respir J 2005;26:948-68.

18 Nabhan D, Bielko S, Sinex JA, et al. Serum ferritin distribution in elite athletes. J Sci Med Sport 2019.

19 Koehler K, Braun H, Achtzehn S, et al. Iron status in elite young athletes: gender-dependent influences of diet and exercise. Eur J Appl Physiol 2012;112:513-23.

20 Fallon KE. Utility of hematological and iron-related screening in elite athletes. Clin J Sport Med 2004;14:145-52.

21 Milman N, Clausen J, Byg K-E. Iron status in 268 Danish women aged 18-30 years: influence of menstruation, contraceptive method, and iron supplementation. Ann Hematol 1998;77:13-19.

22 Alaranta A, Alaranta $\mathrm{H}$, Heliövaara $\mathrm{M}$, et al. Allergic rhinitis and pharmacological management in elite athletes. Med Sci Sports Exerc 2005;37:707-11.

23 Weiler JM, Anderson SD, Randolph C, et al. Pathogenesis, prevalence, diagnosis, and management of exercise-induced bronchoconstriction: a practice parameter. Ann Allergy Asthma Immunol 2010;105:S1-47.

24 Kokko S, Kannas L, Villberg J. The health promoting sports club in Finland: a challenge for the settings-based approach. Health Promot Int 2006;21:219-29. 